\title{
Stepping Up the Fight Against Infant and Maternal Mortality
}

Michelle Winokur, DrPH, and the AfPA Governmental Affairs Team, Alliance for Patient Access (AfPA)

The Alliance for Patient Access (allianceforpatientaccess.org), founded in 2006, is a national network of physicians dedicated to ensuring patient access to approved therapies and appropriate clinical care. AfPA accomplishes this mission by recruiting, training and mobilizing policy-minded physicians to be effective advocates for patient access. AfPA is organized as a non-profit 501(c)(4) corporation and headed by an independent board of directors. Its physician leadership is supported by policy advocacy management and public affairs consultants. In 2012, AfPA established the Institute for Patient Access (IfPA), a related 501(c) (3) non-profit corporation. In keeping with its mission to promote a better understanding of the benefits of the physician-patient relationship in the provision of quality healthcare, IfPA sponsors policy research and educational programming.

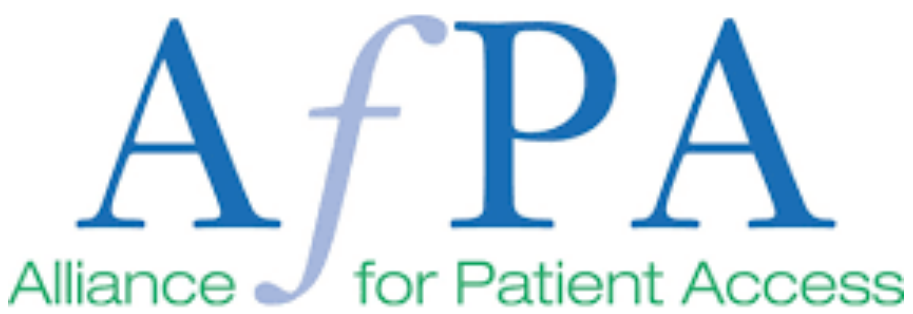

"Among the world's developed countries, the United States holds the unwanted distinction of leading maternal and infant deaths. In an attempt to turn the tide, the federal government announced a new $\$ 350$ million investment last month."

Among the world's developed countries, the United States holds the unwanted distinction of leading maternal and infant deaths. In an attempt to turn the tide, the federal government announced a new $\$ 350$ million investment last month.

Through a series of grants, (1) the government will particularly target the stubborn racial inequity that has long left non-white mothers and babies with higher-than-average mortality rates.

Maternal, Infant, and Early Childhood Home Visiting Program:

Most of the funding, \$342 million, will expand the Maternal, Infant, and Early Childhood Home Visiting Program. As the name implies, the program supports home medical visits to expectant moms and those with young children.

The infant and maternal health experts visit low-income mothers primarily to guide pregnancy health and parenting skills. They also bring essential baby care supplies like diapers and help families secure food, link them to federal nutrition programs, and locate stable or more suitable housing, among other services.

\section{Healthy Start Initiatives:}

Federal funding is also going to the Healthy Start Initiative (2), which operates in communities where the infant death rate is 1.5 times higher than the national average.

Some of the funds will support the increased use of doulas, who provide physical and emotional support to expectant moms and their partners through pregnancy and childbirth. Research shows that doulas support better health outcomes and can reduce cesarean and preterm births. (3)

\section{"A portion of the Healthy Start funding will augment existing support to 10 states participating in the State Systems Developmental Initiative. (4) The program is focused on collecting and reporting timely, high-quality maternal health data, which has long been a challenge."}

A portion of the Healthy Start funding will augment existing support to 10 states participating in the State Systems Developmental Initiative. (4) The program is focused on collecting and reporting timely, high-quality maternal health data, which has long been a challenge.

\section{Persistent Infant and Maternal Mortality:}

Despite progress in recent years, the United States continues to trail other wealthy countries on measures of infant health.

The United States' infant death rate is $71 \%$ higher than average, according to a 2017 study of 12 developed countries. (5) And within the United States, mortality rates among babies born to non-Hispanic Black, Native American, and Alaska Native mothers remain disproportionately high compared to babies born to white mothers.

A similarly discouraging trend persists with maternal mortality, with the United States trailing other wealthy countries in preventing deaths from pregnancy or childbirth. (6) The maternal death rate among non-Hispanic Black women was more than twice as high as that of non-Hispanic white women, according to recent data from the National Center for Health Statistics. (7)

These statistics and the factors that contribute to them are well 
known. "We know that many mothers and their children do not receive the care they need to stay healthy throughout their lives," said Acting HRSA Administrator Diane Espinosa in announcing the new federal awards. "These programs will allow us to better tackle the root causes of these challenges," she added.

Digging deep to address infant and maternal mortality is a must if the United States wants to reverse its current trend - and do right by mothers and infants of all races and classes.

\section{References:}

1. https://www.hhs.gov/about/news/2021/09/17/hhs-announces-350-million-to-strengthen-maternal-child-health-acrossthe-nation.html?utm source=news-releases-email\&utm medium=email\&utm_campaign=sept-19-2021-email-a

2. https://mchb.hrsa.gov/maternal-child-health-initiatives/ healthy-start

3. https://www.npr.org/sections/healthshots/2016/01/15/463223250/doula-support-for-pregnantwomen-could-improve-care-reduce-costs

4. $\quad$ https://www.hrsa.gov/grants/find-funding/hrsa-21-130

5. https://www.healthsystemtracker.org/chart-collection/infantmortality-u-s-compare-countries/\#item-start

6. https://www.commonwealthfund.org/publications/issuebriefs/2018/dec/womens-health-us-compared-ten-othercountries

7. https://www.cdc.gov/nchs/data/hestat/maternal-mortality2021/E-Stat-Maternal-Mortality-Rates-H.pdf

This content article was also published at InstituteforPatientAccess.org Disclosures: Michelle Winokur, $\mathrm{DrPH}$, is the Policy Communications Director for the Alliance for Patient Access.

\section{NT}

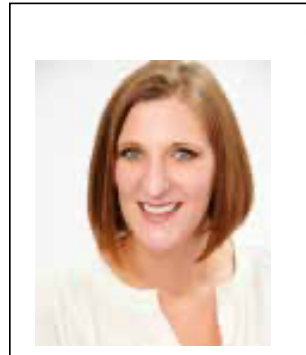

Corresponding Author

Michelle Winokur, DrPH,

Policy Communications Director

Alliance for Patient Access (AfPA) Government Affairs Team

1275 Pennsylvania Ave. NW, Suite 1100A Washington, DC

20004-2417

202-499-4114

Email: info@allianceforpatientaccess.org

\section{Readers can also follow NEONATOLOGY TO via our Twitter Feed @NEOTODAY}
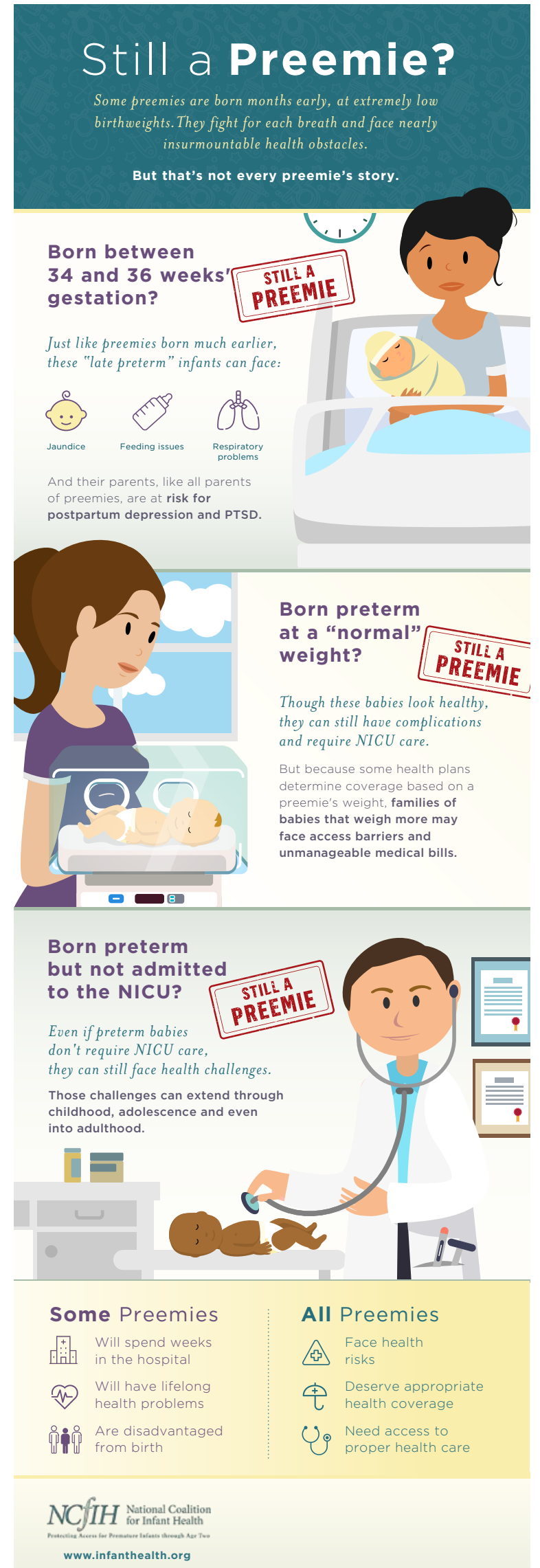